\title{
Perceived Discrimination and Self-Reported Quality of Care Among Latinos in the United States
}

\author{
Debra Perez, $P h D^{7}$, William M. Sribney, $\mathrm{MS}^{2}$, and Michael A. Rodríguez, MD, MPH ${ }^{3}$ \\ ${ }^{1}$ Robert Wood Johnson Foundation, Princeton, NJ, USA; ${ }^{2}$ Third Way Statistics, White Lake, NY, USA; ${ }^{3}$ Department of Family Medicine, UCLA, Los \\ Angeles, CA, USA.
}

\begin{abstract}
BACKGROUND: Given the persistence of health and health-care disparities among Latinos in the United States and evidence that discrimination affects health and health care, an investigation of the relationship between perceived discrimination and quality of health care among Latinos is warranted.
\end{abstract}

OBJECTIVE: To examine the relationship of perceived discrimination (in general and in regard to doctors and medical personnel) with self-reported quality of health care and doctor-patient communication in a nationally representative Latino population sample.

PARTICIPANTS: Participants were 1,067 Latino adults aged $\geq 18$ years living in the US selected via randomdigit dialing. Telephone interviews were conducted in 2008 during Wave 2 of the Pew Hispanic Center/Robert Wood Johnson Foundation Hispanic Healthcare Survey.

RESULTS: US-born Latinos were twice as likely to report general discrimination as foreign born: $0.32 \mathrm{SD}$ versus $-0.23 \mathrm{SD}(P<0.001)$ on the Detroit Area Survey (DAS) discrimination scale. Higher DAS discrimination was associated with lower self-reported quality of care in US-born Latinos [OR=0.5; 95\% CI (0.3, 0.9); $P=0.009]$. For foreign-born Latinos, report of any doctor or medical staff discrimination was associated with lower quality of care $[\mathrm{OR}=0.5 ; 95 \%$ CI $(0.3,0.9)$; $P=0.03]$, but the DAS was not. For US-born Latinos, doctor discrimination and higher DAS were jointly associated with worse doctor-patient communication. For foreign-born Latinos, the effect of discrimination on doctor-patient communication was significantly smaller than that observed in US-born Latinos.

CONCLUSIONS: Given the association between perceived discrimination and quality of care, strategies to address discrimination in health-care settings may lead to improved patient satisfaction with care and possibly to improved treatment outcomes.

KEY WORDS: discrimination; Latinos; disparities; quality; health care. J Gen Intern Med 24(Suppl 3):548-54

DOI: $10.1007 / \mathrm{s} 11606-009-1097-3$

(c) Society of General Internal Medicine 2009

\section{INTRODUCTION}

Minorities in the US are more likely to experience health and health-care disparities than their majority counterparts. While many factors may contribute to these disparities, discrimination has been shown to be one of the most prominent. ${ }^{1,2}$ The body of literature linking discrimination with health and health-care disparities has traditionally concentrated on African Americans, and has only recently begun to focus on the Latino population, ${ }^{3-5}$ perhaps due to recent census findings indicating that the Latino population is the largest minority population in the US. ${ }^{6,7}$ Health-care disparities that Latinos experience as a result of discrimination, and the subsequent effects on quality of health care, present issues of great social and economic significance for the entire populace.

In addition, perceived discrimination has been established as a correlate of health-care access and health-care behavior in a number of ways. Perceived discrimination has been found to be associated with cancer screening ${ }^{8}$, health-care underutilization $^{3}$, receipt of diabetes management indicators such as the hemogloblin A1C test, foot exam and blood pressure exam $^{9}$ and reported delays in filling pharmacy prescriptions ${ }^{10}$. The existence of racial/ethnic and other disparities in care especially among vulnerable populations gives further impetus to understanding how quality of care is impacted by perceived discrimination. Trivedi and Ayanian showed that vulnerable persons who perceived discrimination were less likely to receive testing for CVD, flu shots and eye exams ${ }^{1}$.

Previous studies have examined perceived discrimination among Latinos in the US health-care system. ${ }^{5}$ The 2004 Behavioral Risk Factor Surveillance System survey showed that $5.2 \%$ of Latinos perceived discrimination in health-care settings, while only $2 \%$ of non-Latino whites reported discrimination. ${ }^{11}$ The nature of this discrimination was further elucidated by research ${ }^{5,12}$ that found that Latinos born in the US were more likely to report discrimination based on their sociodemographic and sociocultural factors. However, Latinos with higher socioeconomic status (SES) and health insurance reported experiencing less discrimination when receiving health care. ${ }^{12}$ In contrast, other studies have shown that higher SES is associated with greater perception of discrimination. ${ }^{5}$

Perceived discrimination among Latinos has been shown to produce effects both in and out of the provider's office. In the hospital setting, for example, Latina patients have rated their obstetrical services experience lower than non-Latino whites with regard to respect, information and education, physical 
comfort and emotional support. ${ }^{13}$ The effects of this discrimination have extended well beyond hospitals, however, and have prevented Latinos from seeking health-care services. For example, Nadeem et al. found that for Latinas, an increased stigma in seeking mental health-care services kept them from accessing the services they needed. ${ }^{14}$ Furthermore, perceived discrimination has been related to greater psychological distress and lower self-esteem. ${ }^{15}$ Discrimination has also been associated with conditions such as coronary heart disease, high blood pressure and compromised mental health. ${ }^{4,16,17}$

Despite the existence of the above-mentioned studies, perceived discrimination among the Latino population remains a relatively understudied area. ${ }^{3,5,19}$ Awareness and understanding of discrimination-induced health-care disparities are needed to mobilize systematic and systemic reform efforts. ${ }^{20}$ This study contributes to a growing body of literature examining discrimination among Latinos by using a nationally representative database to examine general and health-carespecific discrimination experienced by specific groups of Latinos in the US. In this study, we examine the association between perceived discrimination and two measures of quality of care: patient report of quality of care in the past 12 months and quality of doctor-patient communication.

\section{METHODS}

\section{Sample}

Study participants were part of a stratified, random-digit dialing telephone survey (the Pew Hispanic Center/Robert Wood Johnson Foundation Latino Health Survey) ${ }^{21}$ of $N=3,899$ adult Latinos (aged $\geq 18$ years) designed to produce a statistically representative sample of Latinos in the contiguous US. Respondents were identified as Latino if they answered yes to the question, Are you, yourself, of Hispanic or Latino origin or descent such as Mexican, Puerto Rican, Cuban, Dominican, Central or South American, Caribbean or some other Latin American background? Initial telephone interviews (Wave 1) were conducted in summer 2007 and had a response rate of $39.5 \%$. Participants were called again in spring 2008 for a second interview (Wave 2), focusing on chronic disorders and medical care received. Subjects for this study are the $N=1,067$ persons who completed the Wave 2 interview.

Wave 1 sampling weights were calculated as the inverse probability of selection. Post-stratification weight adjustment for Wave 2 consisted of an adjustment of Wave 1 sampling weights so that the sum of the weights by sex, age, nativity and education matched those of Latinos in the March 2007 supplement of the Current Population Survey. ${ }^{22}$ This poststratification weight adjustment was minor, and Wave 2 participants were not statistically different from other Wave 1 participants on any demographic measure.

\section{Measures}

For this study, two measures of discrimination were used: the Detroit Area Study (DAS) discrimination scale consisting of nine 6-point items, ${ }^{23,24}$ and a measure of doctor or medical staff discrimination from the Commonwealth Fund Health Quality Survey consisting of three yes or no items; see Appendix for items. ${ }^{25}$ The DAS scale had range 0-39, median 4, mean 6.7, SD 8.4 and Cronbach's $\alpha=0.87$. For all analyses, the DAS discrimination scale was scaled to have mean 0 and SD 1 , and treated as a continuous measure. The doctor or medical staff discrimination items were converted into a single dichotomous variable with zero indicating no to all three items and one indicating a yes to any one of the items.

There were two outcome measures. The first was a 5-point measure of self-reported quality of health care received in the past year, with responses excellent, very good, good, fair and poor. The second outcome measure was a scale comprised of four 5-point items from the Interpersonal Processes of Care Survey Short Form, ${ }^{26}$ which reflects the quality of communication between doctors and other health professionals and the study participant; see Appendix for items. This scale is referred to as the doctor communication scale in this study and had range 0-16, median 10, mean 10.1, SD 4.5 and Cronbach's $\alpha=0.75$.

\section{Statistical Analyses}

Weighted sex-age adjusted means of the DAS discrimination scale were calculated along with weighted sex-age adjusted percentages of respondents who answered yes to any of the doctor discrimination items in Table 1. Significance tests for proportions were performed using a Rao-Scott statistic for the Pearson $\chi^{2}$ test for contingency tables ${ }^{27-29}$, and tests for means were done using design-based Wald tests ${ }^{30}$.

Self-reported quality of care was analyzed as the outcome variable in weighted ordered logistic regressions in Table 2 . The doctor communication scale was the outcome in weighted linear regressions in Table 3. Design-based Wald tests ${ }^{30}$ were conducted to test joint effects of categorical variables. Figures 1 and 2 give adjusted means from weighted regressions. Standard error estimates for all analyses were adjusted for the sampling design using a first-order Taylor series approximation. All analyses were conducted using the svy suite of commands from Stata statistical software version $10.1^{31}$.

\section{RESULTS}

The first data column of Table 1 shows the percentage of respondents who answered yes to any of the three items indicating perception of discrimination from doctors or medical staff in the past 2 years (see Appendix). Overall, only $19 \%$ of all persons reported any discrimination from doctors or medical staff. Doctor or medical staff discrimination was significantly associated with age $(P=0.02)$ with younger persons (18-29 years) more likely to report discrimination $(22 \%)$ than persons aged $\geq 65$ years. The only other significant association of doctor discrimination and the variables shown in Table 1 was between doctor discrimination and selfreported health status $(P=0.005)$. Persons with poor health status reported dramatically more doctor or medical staff discrimination (39\%) than those with better health status (11\% for those reporting excellent health and 14\% for those reporting very good health).

Table 1 shows the mean value of the DAS discrimination scale by demographics and self-reported health status. The overall mean of zero on this scale reflects the standardization of the scale to mean 0 and SD 1. Unstandardized, the overall 
Table 1. Any Reported Discrimination from Doctors or Medical Staff and Mean DAS Discrimination Scale for US Latinos $(N=1,067)$ by Demographics and Self-Reported Health Status

\begin{tabular}{|c|c|c|}
\hline & $\begin{array}{l}\text { Any discrimination } \\
\text { from doctors or } \\
\text { medical staff in past } \\
2 \text { years* } \\
\%\end{array}$ & $\begin{array}{l}\text { Mean DAS } \\
\text { discrimination } \\
\text { scalet }\end{array}$ \\
\hline All persons & $19(2)$ & $0.00(0.05)$ \\
\hline \multicolumn{3}{|l|}{ Sex } \\
\hline Female & $20(3)$ & $-0.09(0.07)$ \\
\hline Male & $18(2)$ & $0.09(0.07)$ \\
\hline (Test of any difference) & 0.5 & 0.07 \\
\hline \multicolumn{3}{|l|}{ Age (years) } \\
\hline $18-29$ & $22(4)$ & $0.30(0.13)$ \\
\hline $30-49$ & $19(2)$ & $-0.04(0.05)$ \\
\hline $50-64$ & $15(3)$ & $-0.27(0.05)$ \\
\hline$\geq 65$ & $9(3)$ & $-0.42(0.10)$ \\
\hline (Test of any difference) & 0.02 & $<0.001$ \\
\hline \multicolumn{3}{|l|}{ Foreign born $\ddagger$ by years in US } \\
\hline $0-5$ & $19(4)$ & $-0.32(0.09)$ \\
\hline $6-15$ & $18(3)$ & $-0.29(0.06)$ \\
\hline$\geq 16$ & $18(5)$ & $-0.12(0.11)$ \\
\hline (Test of any difference) & 1.0 & 0.3 \\
\hline Foreign born, all & $20(2)$ & $-0.23(0.04)$ \\
\hline US born & $16(3)$ & $0.32(0.09)$ \\
\hline (Test of any difference) & 0.3 & $<0.001$ \\
\hline \multicolumn{3}{|l|}{ Language of interview } \\
\hline Spanish or mostly Spanish & $18(2)$ & $-0.22(0.06)$ \\
\hline $\begin{array}{l}\text { English or a mix of English } \\
\text { and Spanish }\end{array}$ & $19(3)$ & $0.31(0.09)$ \\
\hline (Test of any difference) & 0.8 & $<0.001$ \\
\hline \multicolumn{3}{|l|}{ Education } \\
\hline $0-8$ years & $22(4)$ & $-0.14(0.10)$ \\
\hline $9-11$ years & $17(4)$ & $-0.03(0.12)$ \\
\hline High school graduate & $18(3)$ & $-0.05(0.10)$ \\
\hline Some college & $19(4)$ & $0.20(0.10)$ \\
\hline College degree or more & $14(5)$ & $0.01(0.14)$ \\
\hline (Test of any difference) & 0.8 & 0.2 \\
\hline \multicolumn{3}{|l|}{ Self-reported health status } \\
\hline Excellent & $11(4)$ & $-0.12(0.12)$ \\
\hline Very good & $14(3)$ & $0.06(0.12)$ \\
\hline Good & $16(3)$ & $-0.10(0.08)$ \\
\hline Fair & $27(4)$ & $0.12(0.09)$ \\
\hline Poor & $39(12)$ & $-0.02(0.23)$ \\
\hline (Test of any difference) & 0.005 & 0.3 \\
\hline
\end{tabular}

*Age-sex adjusted percentages of respondents who answered yes to any of three questions relating to experiences where doctors or medical staff judged the respondent unfairly or treated the respondent with disrespect because of race or ethnicity, language or financial status. See Appendix for items. Standard errors given in parentheses. Significance of any difference of proportions among categories is tested using the Rao-Scott statistic for the Pearson $\chi^{2}$ test; see Methods.

$\dagger$ Age-sex adjusted mean scores for the DAS discrimination scale standardized to have mean 0 and SD 1. See Appendix for scale items. Standard errors given in parentheses. Significance of any difference of means among categories is tested using an adjusted Wald test; see Methods.

$\ddagger$ Foreign-born includes US citizens who were born on the island of Puerto Rico.

DAS mean was 6.7 (with range 0-39), which corresponds to an average answer slightly below the level of the response "less than once a year" for each of the nine items on the scale (see Appendix). The DAS responses were not significantly different by sex, but were highly associated with age $(P<$ 0.001) with younger participants reporting the most discrimination. US-born Latinos reported more discrimination than the foreign-born, with the US born far more likely to report discrimination compared to the foreign born ( $0.32 \mathrm{SD}$ versus $-0.23 \mathrm{SD}$ ); however, the age-adjusted means for the foreign born did not significantly differ by the number of years in the US. Language of interview was associated with perceived discrimination to a similar degree as nativity, with those who were interviewed in English or a mix of English and Spanish more likely to report discrimination than Spanish interviewees $(0.31$ SD versus -0.22 SD). Reported discrimination on the DAS scale did not differ significantly by education, nor was self-reported health status associated with DAS.

Table 2 shows ordered logistic regression models for selfreported quality of health care in the past year with separate models for US-born and foreign-born Latinos. Included in the models are terms for any discrimination from doctors or medical staff, the standardized DAS discrimination measure (yielding a beta coefficient), demographics, health insurance and self-reported health status. Models for both US-born and foreign-born Latinos yielded the same odds ratio (0.5) for doctor discrimination; however, only in the foreign-born model did it reach statistical significance $(P=0.03)$. The DAS discrimination scale, however, was significantly associated with lower quality of care for the US born [OR=0.5 (0.3, 0.9); $P=0.009$ ], but was not significant for the foreign born $[\mathrm{OR}=0.9(0.7,1.2) ; P=0.6]$. A test of the difference for the DAS odds ratio for the US born compared to the odds ratio for the foreign born was significant at $P=0.03$. In the model for US-born Latinos, the only other significant odds ratio was that for very low education (0-8 years). In contrast, for foreign-born Latinos, younger adults (18-29 years), health insurance and self-reported health status were all significantly associated with quality of care.

Table 3 shows linear regression models for the doctor communication scale (see Appendix). For US-born Latinos, both any doctor or medical staff discrimination and DAS terms were significantly associated $(P<0.001$ and $P=0.03$, respectively) with doctor communication, with persons reporting more discrimination having worse doctor communication. No other terms were significant in the model for the US born. For foreign-born Latinos, these discrimination terms were marginally nonsignificant. A test of the difference for the doctor discrimination coefficient for the US born $[-3.5(-5.1,-2.0)]$ compared to the coefficient for the foreign born $[-1.2(-2.5,0.0)]$ was significant at $P=0.02$. Notably, the only significant term in the foreign-born model was insurance, and only marginally so.

Figures 1 and 2 illustrate the effect size of the self-reported experience of doctor or medical staff discrimination. Figure 1 shows the mean level of self-reported quality of care by nativity for persons reporting any doctor or medical staff discrimination and for those reporting no discrimination. Figure 2 is similar except that the outcome plotted is the mean level of the doctor communication scale. Means in Figure 2 were adjusted for sex, age and education, and means in Figure 1 were adjusted for these variables and self-reported health status as well (see Methods).

In Figure 1, the difference in self-reported quality of care for US-born Latinos who report any doctor discrimination compared to those who report none is 0.7 lower [95\% CI $(0.2,1.2)$; $P=0.004]$, where one unit represents one step on the response (i.e., the difference between very good and good). For foreignborn Latinos, the difference is smaller: 0.4 lower self-reported quality of care [95\% CI $(0.1,0.6) ; P=0.006]$.

In Figure 2, the difference in the doctor communication scale for US-born Latinos who report any doctor discrimination compared to those who report none is 4.1 lower [95\% CI $(2.5,5.6) ; P<0.001]$. For foreign-born Latinos, the difference is 
Table 2. Association of Self-Reported Quality of Care* with Discrimination Measures: Ordered Logistic Regression Models for US Latinos with Any Past-Year Doctor Visits

\begin{tabular}{|c|c|c|c|c|}
\hline & \multicolumn{2}{|c|}{ US born $(N=249)$} & \multicolumn{2}{|c|}{ Foreign born $(N=591) \dagger$} \\
\hline & $\begin{array}{l}\text { Odds ratio } \\
\text { (95\% Cl) }\end{array}$ & $\begin{array}{l}\text { Significance } \\
(P)\end{array}$ & $\begin{array}{l}\text { Odds ratio } \\
(95 \% \mathrm{Cl})\end{array}$ & $\begin{array}{l}\text { Significance } \\
(P)\end{array}$ \\
\hline Any discrimination from doctors or medical staff $\ddagger$ & $0.5[0.2,1.2]$ & 0.1 & $0.5[0.3,0.9]$ & 0.03 \\
\hline DAS discrimination scale§ & $0.5[0.3,0.9]$ & 0.009 & $0.9[0.7,1.2]$ & 0.6 \\
\hline Male & $1.4[0.7,2.8]$ & 0.3 & $1.0[0.7,1.5]$ & 1.0 \\
\hline \multicolumn{5}{|l|}{ Age (years) } \\
\hline $18-29$ & $1.2[0.5,2.6]$ & 0.7 & $0.6[0.4,1.0]$ & 0.04 \\
\hline $30-49$ & 1 & & 1 & \\
\hline $50-64$ & $0.9[0.5,1.9]$ & 0.8 & $0.9[0.5,1.4]$ & 0.5 \\
\hline$\geq 65$ & $2.1[0.7,6.4]$ & 0.2 & $1.3[0.7,2.3]$ & 0.4 \\
\hline (Test of any difference) & & 0.5 & & 0.09 \\
\hline \multicolumn{5}{|l|}{ Education } \\
\hline $0-8$ years & $0.2[0.1,0.8]$ & 0.02 & $0.8[0.5,1.3]$ & 0.4 \\
\hline $9-11$ years & $2.1[0.6,6.6]$ & 0.2 & $1.3[0.8,2.3]$ & 0.3 \\
\hline High school graduate & 1 & & 1 & \\
\hline Some college & $0.8[0.3,1.9]$ & 0.6 & $1.0[0.5,2.1]$ & 1.0 \\
\hline College degree or more & $0.8[0.3,2.1]$ & 0.6 & $1.8[0.9,3.4]$ & 0.1 \\
\hline (Test of any difference) & & 0.047 & & 0.2 \\
\hline \multicolumn{5}{|l|}{ Household income } \\
\hline$\$ 0-14,999$ & $0.9[0.3,2.5]$ & 0.8 & $1.2[0.7,2.0]$ & 0.4 \\
\hline$\$ 15,000-24,999$ & $1.5[0.5,4.8]$ & 0.5 & $0.8[0.5,1.3]$ & 0.3 \\
\hline$\$ 25,000-34,999$ & 1 & & 1 & \\
\hline$\$ 35,000-59,999$ & $0.9[0.3,2.8]$ & 0.9 & $0.7[0.3,1.3]$ & 0.2 \\
\hline$\geq \$ 60,000$ & $1.2[0.3,4.1]$ & 0.8 & $1.0[0.4,2.4]$ & 0.9 \\
\hline (Test of any difference) & & 0.9 & & 0.2 \\
\hline Health insurance & $2.0[0.8,4.9]$ & 0.1 & $1.7[1.1,2.6]$ & 0.01 \\
\hline \multicolumn{5}{|l|}{ Self-reported health status } \\
\hline Excellent & $1.6[0.5,5.2]$ & 0.4 & $3.3[1.3,8.6]$ & 0.01 \\
\hline Very good & $2.0[0.9,4.5]$ & 0.1 & $1.4[0.9,2.4]$ & 0.2 \\
\hline Good & 1 & & 1 & \\
\hline Fair & $1.1[0.4,3.6]$ & 0.8 & $0.5[0.3,0.8]$ & 0.002 \\
\hline Poor & $0.4[0.1,1.5]$ & 0.2 & $0.5[0.2,1.2]$ & 0.1 \\
\hline (Test of any difference) & & 0.1 & & $<0.001$ \\
\hline
\end{tabular}

*Outcome variable is 5-point measure of self-reported quality of health care received in the past 12 months: excellent, very good, good, fair or poor $\dagger$ Foreign born includes US citizens who were born on the island of Puerto Rico

$\ddagger$ Any self-reported discrimination from doctors or medical staff in past 2 years; see Methods

§DAS discrimination scale standardized to have mean 0 and $S D 1$

much smaller: 1.7 lower on the doctor communication scale [95\% CI $(0.7,2.7) ; P=0.001]$.

\section{DISCUSSION}

Perceived discrimination was associated with quality of care measures in this nationally representative sample of US Latinos. However, this association was much stronger among US-born Latinos than among the foreign born. Of all correlates of quality, discrimination had the strongest effect as one in five persons reporting perceived discrimination from medical personnel within the past 2 years. We looked at two measures of discrimination, one a measure of general discrimination, the Detroit Area Study (DAS) discrimination scale, and the other a measure of perceived discrimination from doctors or medical personnel. In a model of self-reported quality of care for USborn Latinos, with both discrimination measures as independent variables, the DAS scale was significantly associated with quality of care (after controlling for sociodemographics and health status), but perceived doctor discrimination was not. In the same model for foreign-born Latinos, only doctor discrimination was associated with self-reported quality of care. In models of the quality of doctor-patient communication, both discrimination measures were significant for the US born, but for the foreign born, both were marginally nonsignificant.

The finding of a greater association between perceived discrimination and self-reported quality of care measures in the US born compared to the foreign born has several possible explanations. The first possibility is that US-born Latinos experience more discrimination than foreign-born Latinos because they interact more closely with non-Latinos in the US and seek health care in the same settings as non-Latinosand that the care they receive in these settings is below the level that they perceive non-Latinos receive.

The second possibility is that US-born Latinos because of their English-language abilities and greater understanding of US culture are more vigilant in monitoring their patientprovider relationship and are better able perceive when receipt of lower quality of care is connected to discrimination than are foreign-born Latinos. It may be that foreign-born Latinos are "protected" from perceiving discrimination. Other studies have suggested a similar protective factor of lower acculturation. ${ }^{5,32,33}$ Previous authors have suggested ethnic identity as one of many possible buffers of discrimination, and foreignborn Latinos may benefit from this factor. ${ }^{34,35}$ However, in this study, we did not find associations among discrimination and education, age or income that were found in prior studies of discrimination. ${ }^{36}$ 
Table 3. Association of Doctor Communication Scale* with Discrimination Measures: Linear Regression Models for US Latinos with Any PastYear Doctor Visits

\begin{tabular}{|c|c|c|c|c|}
\hline & \multicolumn{2}{|l|}{ US born $(N=251)$} & \multicolumn{2}{|l|}{ Foreign born $(N=584) \dagger$} \\
\hline & Coefficient $(95 \% \mathrm{Cl})$ & Significance $(P)$ & Coefficient $(95 \% \mathrm{Cl})$ & Significance $(P)$ \\
\hline Any discrimination from doctors or medical staff & $-3.5[-5.1,-2.0]$ & $<0.001$ & $-1.2[-2.5,0.0]$ & 0.05 \\
\hline DAS discrimination scale§ & $-0.7[-1.2,-0.1]$ & 0.03 & $-0.5[-1.1,0.0]$ & 0.06 \\
\hline Male & $-0.5[-1.7,0.8]$ & 0.5 & $-0.3[-1.1,0.6]$ & 0.5 \\
\hline \multicolumn{5}{|l|}{ Age (years) } \\
\hline $18-29$ & $0.4[-0.9,1.8]$ & 0.5 & $0.2[-0.9,1.2]$ & 0.8 \\
\hline $30-49$ & 0 & & 0 & \\
\hline $50-64$ & $-0.8[-2.3,0.7]$ & 0.3 & $-0.4[-1.5,0.7]$ & 0.4 \\
\hline$\geq 65$ & $-1.4[-3.4,0.6]$ & 0.2 & $-1.0[-2.3,0.3]$ & 0.1 \\
\hline (Test of any difference) & & 0.3 & & 0.4 \\
\hline \multicolumn{5}{|l|}{ Education } \\
\hline $0-8$ years & $-2.3[-5.5,0.9]$ & 0.2 & $-0.3[-1.4,0.9]$ & 0.6 \\
\hline $9-11$ years & $0.0[-1.8,1.9]$ & 1.0 & $0.6[-0.7,1.8]$ & 0.4 \\
\hline High school graduate & 0 & & 0 & \\
\hline Some college & $-0.5[-1.8,0.8]$ & 0.5 & $-0.6[-2.0,0.7]$ & 0.3 \\
\hline College degree or more & $-0.7[-2.4,1.0]$ & 0.4 & $0.1[-1.4,1.5]$ & 0.9 \\
\hline (Test of any difference) & & 0.6 & & 0.5 \\
\hline \multicolumn{5}{|l|}{ Household income } \\
\hline$\$ 0-14,999$ & $-1.4[-3.8,1.0]$ & 0.2 & $-0.6[-1.9,0.7]$ & 0.4 \\
\hline$\$ 15,000-24,999$ & $-1.4[-3.8,0.9]$ & 0.2 & $0.0[-1.3,1.3]$ & 1.0 \\
\hline$\$ 25,000-34,999$ & 0 & & 0 & \\
\hline$\$ 35,000-59,999$ & $-0.6[-2.6,1.3]$ & 0.5 & $0.2[-1.2,1.6]$ & 0.8 \\
\hline$\geq \$ 60,000$ & $-1.3[-3.5,0.9]$ & 0.3 & $0.9[-0.8,2.6]$ & 0.3 \\
\hline (Test of any difference) & & 0.6 & & 0.5 \\
\hline Health insurance & $0.2[-1.6,2.0]$ & 0.8 & $1.0[0.0,1.9]$ & 0.046 \\
\hline
\end{tabular}

*Outcome variable is 4-item scale assessing the quality of doctor-patient communications (range 0-16); see Methods. Exact zeros in table indicate reference categories

$\dagger$ Foreign born includes US citizens who were born on the island of Puerto Rico

$¥$ Any self-reported discrimination from doctors or medical staff in past 2 years; see Methods

$\S D A S$ discrimination scale standardized to have mean 0 and SD 1

The third possibility is that among US-born Latino there is a larger subgroup of "pessimists" regarding their life in the US than among the foreign born-and these pessimists rate their experiences in general more negatively - so they have perceptions both of more discrimination and of lower quality of health care.

Based on our results, the third possibility seems the least likely. We found that levels of perceived discrimination from doctors or medical staff to be similar among the US born and

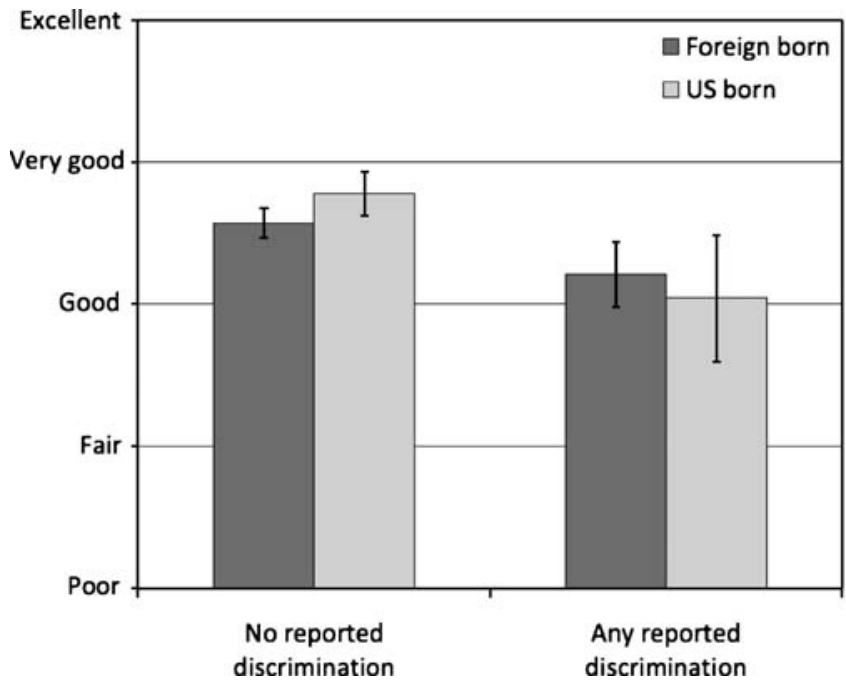

Figure 1. Self-reported quality of care by reported discrimination from doctors or medical staff for US Latinos (adjusted for sex, age, education, insurance and self-reported health status). the foreign born. If there were more "pessimists" among the US born, there should be a larger proportion reporting discrimination in the health-care setting among the US born than among the foreign born. The strongest association that we found was between perceived doctor or medical staff discrimination and doctor-patient communication in the US born. This seems to support the second possibility that US-born Latinos are better able to perceive the connection between

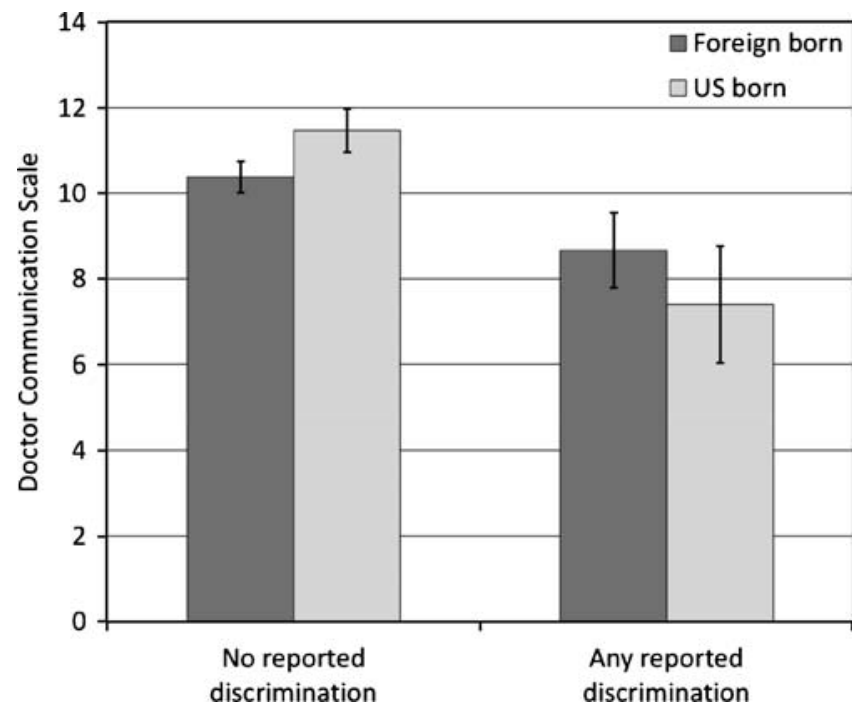

Figure 2. Doctor communication scale by reported discrimination from doctors or medical staff for US Latinos (adjusted for sex, age, education and insurance). 
discrimination and lower quality of care when it exists. The strong association between general discrimination (as measured on the DAS scale) and self-reported lower quality of care among the US born seems to support the first possibilitythose with the most interaction with US culture experience both more discrimination and a perceived lower relative quality of care.

Still a fourth possible explanation explaining why US born Latinos who perceive discrimination report lower quality of care could be that they have switched providers in the previous year. It is likely that many Latinos experienced discrimination prior to the year in which the health-care quality questions referred to. This in turn may explain for the higher rates of perceived discrimination as well as the lower rates of perceived quality of health care received.

The association this study found between poor self-reported health status and perceptions of discrimination from doctors or medical staff is of concern. In Piette et al.'s ${ }^{37}$ work with diabetic patients, a similar association was found where $14 \%$ of the study's participants reported experiencing health-care discrimination during the prior year, including discrimination due to their race $(8 \%)$, education or income $(9 \%)$, age $(7 \%)$ and sex (10\% of women). In the present study, respondents with poorer health status reported more than three and a half times the rate of discrimination in the health-care context.

\section{Limitations}

The study is cross-sectional, and arguments of causation cannot be made. The mean of general discrimination assessed on the DAS scale is relatively low; on average, discriminatory experiences are occurring only a few times a year, and only about one in five Latinos reported any discrimination from doctors or medical personnel in the past 2 years. The question remains whether such a small level of discrimination can be clinically significant. However, it may be that attributes of poor quality of care and poor patient-provider communication, such as rushed care, rudeness, or arrogance on the part of doctors or medical staff, are associated in respondents' minds with perceived discrimination. The connection between general discrimination not necessarily in a medical setting and quality of care may be even more tenuous.

Looking at general discrimination and discrimination in a medical setting jointly in models as we have done may give some insight into possible factors explaining the association. Although the DAS discrimination scale and the doctor discrimination measure had a strong positive association with each other, they were not so collinear as to create problems in the models presented here; when the discrimination terms were included in the models separately, results were similar.

As in all telephone surveys, the representativeness of the study sample to Latinos in general can be questioned. Wave 2 follow-up was also limited in this study; due to financial constraints there was a short time window for completing callbacks. However, our analysis of the Wave 2 sample compared to the rest of the Wave 1 showed no significant differences on any demographic characteristic. Sample size may have been a greater limitation. Our sample size was insufficient to fully dissect the associations among general discrimination, doctor discrimination and quality of care and to identify the subgroups within the nativity groups that were responsible for the overall associations found.

\section{CONCLUSIONS}

The results from this study give a better understanding of the relationship between perceived discrimination and perceived quality of care among US Latinos. It demonstrated that factors such as discrimination may impinge on quality of care. For health-care providers and policymakers seeking to have an impact on health-care quality, focusing on discrimination may prove to be a fruitful endeavor. Discrimination toward both highly acculturated English-speaking US-born Latinos and lower-acculturated Spanish-speaking Latinos should be addressed. Future research is needed to investigate how interventions can be tailored so that they address perceived discrimination in health-care experiences for Latinos, perhaps with different approaches for the US born than the foreign born. Reducing discrimination may be difficult to achieve, but the results of this study suggest that quality improvement interventions must take discrimination into account.

Acknowledgments: This work was supported by the Network for Multicultural Research on Health and Healthcare, Dept. of Family Medicine - UCLA David Geffen School of Medicine, funded by the Robert Wood Johnson Foundation. Dr. Rodriguez also received support from the DREW/UCLA Project EXPORT, NCMHD, P2OMDOOO148/ P2OMDO00182. Dr. Perez would like to thank Dr. Edith Arrington and Diane Martinez for their reviews and suggestions.

Corresponding Author: Michael A. Rodríguez, MD, MPH; 10880 Wilshire Blvd, Suite 1800, Los Angeles, CA 90024, USA (e-mail: MRodriguez@mednet.ucla.edu).

\section{REFERENCES}

1. Trivedi AN, Ayanian JZ. Perceiveddiscrimination and use of preventive health services. J Gen Intern Med. 2006;21(6):553-8.

2. Stuber J, Galea S, Ahern J, Blaney S, Fuller C. The association between multiple domains of discrimination and self-assessed health: A multilevel analysis of Latinos and Blacks in four low-income New York City neighborhoods. Health Serv Res. 2003;38:1735-60.

3. Burgess DJ, Ding $\mathbf{Y}$, Hargreaves $\mathbf{M}$, van Ryn $\mathbf{M}$, Phelan $\mathbf{S}$. The association between perceived discrimination and underutilization of needed medical and mental health care in a multi-ethnic community sample. J Health Care Poor Underserved. 2008;19:894-911.

4. Williams DR, Harold W, Neighbors HW, Jackson JS. Racial/ethnic discrimination and health: findings from community studies. Am J Public Health. 2003;93:200-8.

5. Pérez DJ, Fortuna L, Alegria M. Prevalence and correlates of everyday discrimination among U.S. Latinos. J Community Psychol. 2008;36:421-33.

6. Bernstein R. Nation's Population One-Third Minority. US Census Bureau. 2006. http://www.census.gov/Press-Release/www/releases/archives/ population/006808.html. Accessed December 20, 2008.

7. Bernstein R. US Hispanic Population Surpasses 45 Million Now 15 Percent of Total. US Census Bureau. 2008. http://www.census.gov/ Press-Release/www/releases/archives / population/006808.html. Accessed December 20, 2008.

8. Crawley LM, Ahn DK, Winkleby MA. Perceived medical discrimination and cancer screening behaviors of racial and ethnic minority adults. Cancer Epidemiol Biomarkers Prev. 2008;17(8)

9. Ryan AM, Gee GC, Griffith D. The effects of perceived discrimination on diabetes management. J Health Care Poor Underserved. 2008;19:149-63.

10. Van Houtven CH, Voils CI, Oddone EZ, Weinfurt KP, Friedman JY, Schulman KA, Bosworth HB. Perceived Discrimination and Reported Delay of Pharmacy Prescriptions and Medical Tests

11. Hausmann LRM, Jeong K, Bost JE, Ibrahim SA. Perceived discrimination in health care and health status in a racially diverse sample. Med Care. 2008;46:905-14.

12. Lauderdale DS, Wen M, Jacobs EA, Kandula NR. Immigrant perceptions of discrimination in health care: The California Health Interview Survey 2003. Med Care. 2006;44:914-20. 
13. Hicks LS, Ayanian JZ, Orav EJ, Soukup J, et al. Is hospital service associated with racial and ethnic disparities in experiences with hospital care? Am J Med. 2005; 118:529-35.

14. Nadeem E, Lange JM, Edge D, Fongwa M, Belin T, Miranda J. Does stigma keep poor young immigrant and US-born black and Latina women from seeking mental health care? Psychiatr Serv. 2007;58:1547-54.

15. Moradi B, Risco C. Perceived discrimination experiences and mental health of Latina/o American persons. J Couns Psychol. 2006;53:11-421.

16. Williams DR, Collins C. US socioeconomic and racial differences in health: Patterns and explanations. Annu Rev Sociol. 1995;21:349-86.

17. Krieger N, Sidney S. Racial discrimination and blood pressure; the CARDIA study of young Black and White adults. Am J Public Health. 1996;86A(10):1370-78.

18. Guinier L, Torres G. The Miner's Canary: Enlisting Race, Resisting Power, Transforming Democracy. Cambridge, Mass: Harvard University Press; 2003.

19. Viruell-Fuentes EA. Beyond acculturation: Immigration, discrimination, and health research among Mexicans in the United States. Soc Sci Med. 2007;65:1524-35.

20. Lillie-Blanton M, Brodie M, Rowland D, et al. Race, ethnicity, and the health care system: public perceptions and experiences. Med Care Res Rev. 2000;57(Supplement 1):218-35.

21. PewResearchCenter Project. Hispanics and Health Care in the United States: Access, Information and Knowledge. Washington, DC: A Joint Pew Hispanic Center and Robert Wood Johnson Foundation Research Report; 2008.

22. Bureau of the Census for the Bureau of Labor Statistics. Washington, DC: US Census Bureau, 2007.

23. Jackson J, Williams D, Torres M. Chapter 8: Perceptions of discrimination, health and mental health: The social stress process. In:Maney A, Ramos J(eds.), Socioeconomic Conditions, Stress and Mental Disorders: Toward a New Synthesis of Research and Public Policy. Ann Arbor, MI: University of Michigan, Institute for Social Research. Available at: http://www.mhsip.org/pdfs/jackson.pdf. Accessed December 10, 2008.

24. Williams DR, Yu Y, Jackson JS, Anderson NB. Racial differences in physical and mental health. J Health Psychol. 1997;2:335-51.

25. Ngo-Metzger Q, Telfair J, Sorkin DH. Cultural Competency and Quality of Care: Obtaining the Patient's Perspective; Commonwealth Fund Report. 2006

26. Stewart AL, Nápoles-Springer AM, Gregorich SE, Santoyo-Olsson J. Interpersonal processes of care survey: patient-reported measures for diverse groups. Health Serv Res. 2007:42(3 Pt 1):1235-56.

27. Rao JNK, Scott JA. On chi-squared tests for multiway contingency tables with cell poportions estimated from survey data. Ann Stat. 1984;12:46-60.

28. Rao JNK, Thomas DR. "Chi-squared tests for contingency tables". In: Skinner CJ, Holt D, Smith TMF, eds. Analysis of complex surveys. New York: John Wiley \& Sons; 1989: 89-114.

29. Sribney W. Two-way contingency tables for survey or clustered data Stata J. 1998;45:33-49.

30. Korn E, Graubard B. Simultaneous testing of regression coefficients with complex survey data: Use of Bonferroni $t$ statistics. Am Stat. 1990;44:270-276.

31. Stata Statistical Software Version 10.1 [computer program]. College Station, TX.; 2008.

32. Vega WA, Koury EL, Zimmerman RS, Gil AG, Warheit GJ. Culture conflict and problem behaviors of Latino adolescents in home and school settings. J Commun Psychol. 1995;23:167-79.

33. Gee GC, Spencer M, Chen J, Yip T, Takeuchi DT. The association between self-reported racial discrimination and 12-month DSM-IV mental disorders among Asian Americans nation wide. Soc Sci Med. 2007;64:1984-96.

34. Mossakowski K. Coping with perceived discrimination: does ethnic identity protect mental health? J Health Soc Behav. 2003;44:318-31.

35. Gee GC, Spencer M, Chen J, Takeuchi DT. A nationwide study of discrimination and chronic health conditions among Asian Americans. Am J Public Health. 2007;97:1275-82.

36. Kessler RC, Michelson KD, Williams DR. The prevalence, distribution and mental health correlates of perceived discrimination in the United States. J Health Soc Behav. 1999;40:208-30

37. Piette JD, Bibbins-Domingo $\mathbf{K}$, Schillinger $\mathbf{D}$. Health care discrimination, processes of care, and diabetes patients' health status. Patient Educ Couns. 2006;60(1):41-8.

\section{APPENDIX}

Detroit Area Survey (DAS) Discrimination Scale

This scale ${ }^{22,23}$ is based on responses to the following nine items:

In your day-to-day life how often have any of the following things happened to you:

a. You are treated with less courtesy than other people.

b. You are treated with less respect than other people.

c. You receive poorer service than other people at restaurants or stores.

d. People act as if they think you are not smart.

e. People act as if they are afraid of you.

f. People act as if they think you are dishonest.

g. People act as if they they're better than you are.

h. You are called names or insulted.

i. You are threatened or harassed.

Would you say this has happened to you...?

(5) Almost every day

(4) At least once a week

(3) A few times a month

(2) A few times a year

(1) Less than once a year, or

(0) Never

\section{Doctor or Medical Staff Discrimination}

This measure, derived from questions from the Commonwealth Fund Health Quality Survey ${ }^{24}$, is based on yes or no responses to the following three items:

Now, thinking about all of the experiences you have had with health-care visits in the last 2 years, have you ever felt that the doctor or medical staff you saw judged you unfairly or treated you with disrespect because of...

a. Your race or ethnic background

b. How well you speak English

c. Your ability to pay for the care or the type of health insurance you have

The discrimination measure constructed from these items and used in all analyses was a dichotomous variable with 1 indicating a "yes" answer to any of these three items and 0 indicating "no" answers to all three items.

Doctor Communication Scale

This scale was based on the following four items from the Interpersonal Processes of Care Survey Short Form ${ }^{25}$,

How often did doctors or health professionals...

a. Really find out what your concerns were

b. Clearly explain their advice and recommendations

c. Clearly explain the side effects of the medication(s)

d. Ask if you were having problems following their advice and recommendations

Would you say...?

(0) Never

(1) Rarely

(2) Sometimes

(3) Usually, or

(4) Always 